Elsevier Editorial System(tm) for Fluid Phase Equilibria Manuscript Draft

Manuscript Number: FPE-D-09-00045R1

Title: GIBBS ENERGY BASED PROCEDURE FOR THE CORRELATION OF TYPE 3 TERNARY SYSTEMS INCLUDING A THREE-LIQUID PHASES REGION

Article Type: Full Length Article

Keywords: LLLE; LLE; data correlation; type 3 systems; tie-triangle; NRTL

Corresponding Author: Dr. Juan A. Reyes-Labarta,

Corresponding Author's Institution: University of Alicante

First Author: Antonio Marcilla

Order of Authors: Antonio Marcilla; María del Mar Olaya; María Dolores Serrano; Raúl Velasco; Juan A. Reyes-Labarta 


\title{
GIBBS ENERGY BASED PROCEDURE FOR THE CORRELATION OF TYPE 3 \\ TERNARY SYSTEMS INCLUDING A THREE-LIQUID PHASES REGION
}

A. Marcilla, M.M. Olaya, M.D. Serrano, R. Velasco and J.A. Reyes-Labarta*.

Chemical Engineering Department, University of Alicante, Apdo. 99, Alicante 03080, Spain. Telf. (34) 965

903789 Fax (34)965 903826.e-mail: ja.reyes@ua.es

\begin{abstract}
Equilibrium data for type 3 ternary systems comprising a liquid-liquid-liquid equilibrium region (LLLE tie-triangle) are not frequently correlated, as is evidenced by a lack of studies in the literature. In the present paper, a robust algorithm to calculate or correlate equilibrium data for this type of system is proposed. This algorithm is based on geometric aspects related to the Gibbs energy of mixing $\left(\mathrm{g}^{\mathrm{M}}\right)$ and possesses some interesting advantages that are discussed in the text. The methodology put forward is applied to correlate the equilibrium data of three type 3 ternary systems. The NRTL model is used to define $\mathrm{g}^{\mathrm{M}}$, and the common tangent plane criterion to define the equilibrium condition for the calculations. The lack in flexibility of the NRTL equation to model these systems is discussed.
\end{abstract}

Keywords: LLLE; LLE; data correlation; type 3 systems; tie-triangle; NRTL. 


\title{
GIBBS ENERGY BASED PROCEDURE FOR THE CORRELATION OF TYPE 3 \\ TERNARY SYSTEMS INCLUDING A THREE-LIQUID PHASES REGION
}

\author{
A. Marcilla, M.M. Olaya, M.D. Serrano, R. Velasco and J.A. Reyes-Labarta*. \\ Chemical Engineering Department, University of Alicante, Apdo. 99, Alicante 03080, Spain. Telf. (34) 965 \\ 903789 Fax (34) 965 903826.e-mail: ja.reyes@ua.es
}

\section{Introduction}

Liquid or solvent extraction normally involves the use of systems composed of at least three substances (ternary systems). The classification of ternary systems with reference to liquid phase equilibria [1] involves type 1,2 and 3 systems; where one, two or three binary subsystems, respectively, are partially miscible. For each one of these groups of systems, the composition ternary diagram (for example the equilateral-triangle representation) may exhibit different behaviours depending on the temperature.

In type 3 ternary systems, the three LLE regions that expand into the ternary diagram away from the binary subsystems may remain separate (Fig.1a), or intersect (Fig. 1b, c) to possibly form one region where three the liquid phases coexist in equilibrium (LLL) (Fig.1c). Systems exhibiting a LLLE region (tie-triangle) are of considerable interest for a number of industrial processes, particularly those involving surfactants. These systems find application in the production of cosmetics, drugs, herbicides, paints, lubricants, etc. [2]. They are especially important in the petroleum engineering industry where surfactants are used to recover residual oil [3-5]. Usually, systems which are effective in improving oil recovery are characterized by three-liquid equilibrium phases which appear and disappear as the concentration of one or more components is varied over ranges that are encountered during displacement through porous media [6]. The design of chemical flooding processes and the 
interpretation of process performance require an understanding of the phase behaviour of these systems $[7,8]$.

The amount of literature on the modelling of LLLE using an excess Gibbs energy model is rather limited. There are only a few studies regarding the numerical solution of the threeliquid equilibrium problem $[6,9,10]$. Stateva et al. [2] discussed the difficulties and dangers associated with the correct determination of the LLLE solution when local optimisation methods are used. They proposed an algorithm for calculating the LLLE, and it was applied to calculate, and not correlate, the tie-triangle of two systems. Problems that could arise from the location of the global mixture were also discussed. Heidemann and Abdel-Ghani [11] used NRTL [12] to model the LLLE in water + phenol + n-hexane. Some papers dealing with surfactant flooding correlate only the LLLE tie-triangles in water (brine) + surfactant + oil mixtures for different salt concentrations. For example, Huan et al. [5] fitted tie-triangles for the quaternary system water + benzene + caprolactam + ammonium sulphate at different temperatures using the extended electrolyte NRTL equation. However, equilibrium data for type 3 ternary systems are not commonly correlated over the whole composition range including the LLE and LLLE regions. In this sense the DECHEMA Chemistry Data Series, Liquid-Liquid Equilibrium Data Collection [13] does not return any result for the correlation of type 3 ternary systems, while NRTL and UNIQUAC [14] binary parameters are given for almost all type 1 and 2 ternary systems. Additionally, the DECHEMA Data Preparation Package (DPP, DECHEMA e.V.), a software package for the regression of thermophysical properties, has also been evaluated on its ability to regress phase equilibrium data for type 3 ternary systems. It turns out that this software is not able to calculate the ternary tie-triangle for these systems, producing LL tie-lines that cross one another in the region where the LLLE would be the most stable solution, and showing that this possibility was not considered in the 
commercial program design. All these facts point to the existence of substantial difficulty in the correlation of this type of ternary systems.

In the present paper, we describe a robust new algorithm for the simultaneous phase equilibrium data correlation of type 3 ternary systems including a LLLE region (tie-triangle). The method is based on the necessary and sufficient Gibbs common tangent plane criterion for ternary systems, equivalent to the global minimization of the Gibbs free energy of mixing, which avoids local or metastable solutions. Also, our approach possesses some interesting differences from other algorithms for liquid phase equilibria calculations that will be highlighted later on: 1) The topology of the $\mathrm{g}^{\mathrm{M}}$ surface is the key factor in the calculations, and 2) a global mixture definition is not necessary. The efficiency of the correlation algorithm is illustrated with three examples. The NRTL model has been used to formulate the excess Gibbs energy, but any other model could be used. The capacity of the NRTL model to correlate type 3 ternary systems including a LLLE region is also discussed.

\section{Algorithm proposed for LLLE calculations}

The calculation or correlation of a type 3 ternary system including a LLLE region involves both, the three separate LLE regions and the LLLE tie-triangle. In this section, we will describe the algorithm that we have proposed for the LLLE calculation, which forms part of a global strategy for simultaneous correlation of the equilibrium data in all the regions (LL and LLL) of this type of system, as explained elsewhere in this paper.

The algorithm proposed for LLLE calculations is based on the Gibbs common tangent plane equilibrium condition for ternary mixtures. Gibbs proved that a necessary and sufficient condition for the absolute stability of a ternary mixture at a fixed temperature, pressure and overall composition is that the Gibbs energy of mixing $\left(\mathrm{g}^{\mathrm{M}}\right)$ surface at no point be below the 
plane tangent to the surface at the given overall composition [15]. In keeping with this criterion, the topological condition required for the Gibbs energy surface $\mathrm{g}^{\mathrm{M}}$, defined by any model, to reproduce the equilibrium of type 3 ternary systems including a LLLE region, is the existence of three points on the $\mathrm{g}^{\mathrm{M}}$ surface having a common tangent plane as well as partial miscibility of the three binary subsystems. Fig. 2 represents an example of a $\mathrm{g}^{\mathrm{M}}$ surface that is consistent with this type of system and which has been calculated using the NRTL model.

The proposed LLLE calculation is performed by intersecting the $\mathrm{g}^{\mathrm{M}}$ ternary surface with successive planes to obtain three separate regions, progressively smaller, to which the required equilibrium compositions are confined. If the algorithm was executed repeatedly, the regions would become small enough so as to represent the actual LLLE solution. However, we use this algorithm, instead, to find three separate and small composition regions where the three equilibrium phases are located. Afterwards, the equilibrium equations based on the common tangent plane criterion proposed by Iglesias-Silva et al. [16] are solved taking into account the restriction on each liquid phase composition to belong to only one of three such regions.

To gain a better understanding of the algorithm put forward, we will illustrate it first for a binary LLE system, and then, after that, extend it to the tie-triangle calculation of a type 3 ternary system. The following steps of the procedure are based on an analysis of the $\mathrm{g}^{\mathrm{M}}$ versus composition curve:

1. In such a binary system points $a$ and $b$ represent the two inflection points of the $\mathrm{g}^{\mathrm{M}}$ curve and can be located by looking for the intersections of the second derivatives of $\mathrm{g}^{\mathrm{M}}$ with the $\mathrm{x}$-axis. Both inflection points define a straight line $\mathrm{L} 1$ which is secant to the $\mathrm{g}^{\mathrm{M}}$ curve (Fig.3).

2. If the difference between $\mathrm{L} 1$ and $\mathrm{g}^{\mathrm{M}}$ is evaluated over the whole composition range, two separate composition regions are obtained for which this difference $\mathrm{L} 1-\mathrm{g}^{\mathrm{M}}$ is 
positive. The points A1 and A2, with the maximum distance between the straight line $\mathrm{L} 1$ and the $\mathrm{g}^{\mathrm{M}}$ curve in both of the separate regions, will be very close to the equilibrium points (B1 and B2) as can be observed in the magnifications included in Fig. 3.

3. The algorithm can be stopped at this point, since two separate composition zones have already been defined where each one of both LL equilibrium phases must be present, and very valuable initial values (points A1 and A2 in Fig. 3) for the LLE calculation have now been obtained. An alternative approach would be to draw a new straight line L2 defined by the points of maximum distance A1 and A2, where two new maximum distance points A3 and A4 would be located, closer to the LL equilibrium points (B1 and $\mathrm{B} 2$ ) than $\mathrm{A} 1$ and $\mathrm{A} 2$. The entire procedure could then be executed repeatedly, until the desired precision is reached.

This strategy outlined above for calculating LLE in binary systems can be extended to the LLLE (tie-triangle) calculation in ternary systems. The steps of the proposed method are detailed below (Figures 4 and 5):

i. The global minimum of the $\mathrm{g}^{\mathrm{M}}$ surface $\left(\mathrm{g}^{\mathrm{M}}{ }_{\text {min }}\right)$ is identified.

ii. The two binary equilibrium points (B1 and B2) are located for each one of the three binary subsystems included in the ternary system.

iii. The two $\mathrm{g}^{\mathrm{M}}$ curves, one in each of the cross-sections ( $\mathrm{S} 1$ or S2) containing a binary liquid phase (B1 or B2) as well as the $\mathrm{g}^{\mathrm{M}}$ global minimum (i.e. B1-g ${ }^{\mathrm{M}}$ Min or $\mathrm{B} 2-\mathrm{g}^{\mathrm{M}}{ }_{\text {Min }}$ ), are inspected for all three of the binary subsystems. The binary subsystem for which both of the $\mathrm{g}^{\mathrm{M}}$ curves have two inflection points is selected (1-3 binary subsystem in Fig. 4).

iv. The $\mathrm{g}^{\mathrm{M}}$ global minimum and the $\mathrm{g}^{\mathrm{M}}$ equilibrium points for the selected binary subsystem (B1 and B2) define a plane P1, which intersects the $\mathrm{g}^{\mathrm{M}}$ surface (Fig. 5). 
v. If the intersection between the plane $\mathrm{P} 1$ and $\mathrm{g}^{\mathrm{M}}$ surface defines three separate regions (Fig. 5), all of these regions must each contain one of the three composition points of the LLLE (confinement of the tie-triangle). Evidently the common tangent plane to the $\mathrm{g}^{\mathrm{M}}$ surface (the LLLE solution) must have lower values of $\mathrm{g}^{\mathrm{M}}$ than $\mathrm{P} 1$. Therefore, the distance between this plane $\mathrm{P} 1$ and the $\mathrm{g}^{\mathrm{M}}$ surface is evaluated over the whole composition diagram, and the points D1, D2 and D3 of maximum distance between the plane $\mathrm{P} 1$ and the $\mathrm{g}^{\mathrm{M}}$ surface in the three separate regions, located previously, thus obtained. These three points D1, D2 and D3 are very close to the LLL equilibrium points, as can be seen by comparing Figures 2 and 5 .

vi. At this point the algorithm allows for two options:

a. Since three separate composition zones have already been identified which each must include one of the liquid phases corresponding to the LLLE solution, and very valuable initial values (D1, D2 and D3) for calculating equilibrium compositions have also been obtained, any adequate equilibrium calculation can be performed.

For example, the Newton-Raphson method is used here to find the LLLE solution by solving Eq. 5-10 (section 3) in the constrained composition areas defined by the intersection between the $\mathrm{g}^{\mathrm{M}}$ surface and $\mathrm{P} 1$, using the set of maximum distance points (D1, D2 and D3) as initial values in the solution of the system of equilibrium equations.

b. The second option, analogous to that explained earlier for binary systems, would be to draw a new plane $\mathrm{P} 2$ defined by the three maximum distance points (D1, D2 and D3). The plane P2 would be closer than P1 to the common tangent plane to the $\mathrm{g}^{\mathrm{M}}$ surface in the LLLE region (tie-triangle solution). This plane would provide three smaller composition zones than P1 in 
which to find the equilibrium solution. Steps v and vi-b could then be repeated until the desired precision for the equilibrium calculation has been achieved. Proceeding in this fashion, the LLLE solution can be determined geometrically.

In some cases, the proposed set of parameters along the calculation process, define a $\mathrm{g}^{\mathrm{M}}$ surface topology that does not give rise to three separate regions when it is intersected with the plane P1 (defined in step iv). Fig. 6 is an example of this where only two separate regions appear when the surface is intersected with P1. In these cases, the plane P2 is defined as follows:

vii. P2 is defined using three new points $(i, j, h)$, calculated as the barycentre of three triangles (Fig. 7): $\left[\mathrm{g}^{\mathrm{M}}{ }_{\text {Min }}, a, c\right],[B 1, b, e]$ and $[B 2, d, f]$, where $a$ and $b, e$ and $f$ are the inflection points of the $\mathrm{g}^{\mathrm{M}}$ curves in the plane sections $\mathrm{S} 1$ and $\mathrm{S} 3$, respectively, and $c$ and $d$ are the points of intersection between the plane $\mathrm{P} 1$ and the $\mathrm{g}^{\mathrm{M}}$ curve in plane section S2. Fig. 8 shows that, using this new P2 plane, three separate composition zones are immediately obtained in which each of the three liquid equilibrium points are closely confined.

viii. If there still were fewer than three separate regions, step vii is repeated: the nonexisting points of intersection are then replaced by the inflection points. Otherwise, the algorithm returns to step $\mathrm{v}$.

The LLLE solution, which is to be calculated, and corresponds to the NRTL parameters used for the chosen examples, has been pre-evaluated and included in the illustration of the algorithm in Figures 5 to 8 in order to provide a better understanding of the evolution of the algorithm as it progressively approaches such a LLLE solution.

The algorithm put forward has the advantage that no global mixture or feed definition is required for the region inside the tie-triangle that must be calculated. The problems associated 
with the dependence on the feed composition definition are discussed in the literature [2]. The algorithm improves the convergence of the numerical methods, which are very sensitive to initial-guess values, and has the additional advantage of avoiding the trivial solution.

\section{Data correlation procedure.}

For liquid mixtures, the dimensionless Gibbs energy of mixing $\left(\mathrm{g}^{\mathrm{M}}\right)$ can be formulated as:

$$
\mathrm{g}^{\mathrm{M}}=\frac{\mathrm{G}^{\mathrm{E}}}{\mathrm{RT}}+\sum_{\mathrm{i}} \mathrm{x}_{\mathrm{i}} \ln \mathrm{x}_{\mathrm{i}}
$$

where the NRTL model has been used here to obtain the excess Gibbs energy $\left(\mathrm{G}^{\mathrm{E}}\right)$. The model includes the corresponding binary parameters $\left(\mathrm{A}_{\mathrm{ij}}\right)$ that are to be calculated via simultaneous correlation of the equilibrium data for all the regions (LL and LLL) of the system. A constant value for the NRTL non-randomness parameter alpha $\left(\alpha_{\mathrm{ij}}\right)$ is frequently used in the literature [17].

\subsection{Equilibrium conditions}

The common tangent plane criterion has been used as equilibrium condition. Assuming that the molar Gibbs energy is a function of the mole fraction, the corresponding non-linear equations that have to be solved simultaneously for all the equilibrium regions can be formulated as follows [16]:

- LL region

$$
\mathrm{F}_{1} \equiv\left(\frac{\partial \mathrm{g}^{\mathrm{M}}}{\partial \mathrm{x}_{1}}\right)_{\mathrm{T}, \mathrm{P}, \mathrm{x}_{2}}^{\alpha}-\left(\frac{\partial \mathrm{g}^{\mathrm{M}}}{\partial \mathrm{x}_{1}}\right)_{\mathrm{T}, \mathrm{P}, \mathrm{x}_{2}}^{\beta}=0
$$




$$
\begin{aligned}
& \mathrm{F}_{2} \equiv\left(\frac{\partial \mathrm{g}^{\mathrm{M}}}{\partial \mathrm{x}_{2}}\right)_{\mathrm{T}, \mathrm{P}, \mathrm{x}_{1}}^{\alpha}-\left(\frac{\partial \mathrm{g}^{\mathrm{M}}}{\partial \mathrm{x}_{2}}\right)_{\mathrm{T}, \mathrm{P}, \mathrm{x}_{1}}^{\beta}=0 \\
& \mathrm{~F}_{3} \equiv\left(\mathrm{g}^{\mathrm{M}, \beta}-\mathrm{g}^{\mathrm{M}, \alpha}\right)-\left(\mathrm{x}_{1}{ }^{\beta}-\mathrm{x}_{1}{ }^{\alpha}\right)\left(\frac{\partial \mathrm{g}^{\mathrm{M}}}{\partial \mathrm{x}_{1}}\right)_{\mathrm{T}, \mathrm{P}, \mathrm{x}_{2}}^{\alpha}-\left(\mathrm{x}_{2}{ }^{\beta}-\mathrm{x}_{2}{ }^{\alpha}\right)\left(\frac{\partial \mathrm{g}^{\mathrm{M}}}{\partial \mathrm{x}_{2}}\right)_{\mathrm{T}, \mathrm{P}, \mathrm{x}_{1}}^{\alpha}=0
\end{aligned}
$$

\section{- LLL region}

$$
\begin{aligned}
& \mathrm{F}_{4} \equiv\left(\frac{\partial \mathrm{g}^{\mathrm{M}}}{\partial \mathrm{x}_{1}}\right)_{\mathrm{T}, \mathrm{P}, \mathrm{x}_{2}}^{\alpha}-\left(\frac{\partial \mathrm{g}^{\mathrm{M}}}{\partial \mathrm{x}_{1}}\right)_{\mathrm{T}, \mathrm{P}, \mathrm{x}_{2}}^{\beta}=0 \\
& \mathrm{~F}_{5} \equiv\left(\frac{\partial \mathrm{g}^{\mathrm{M}}}{\partial \mathrm{x}_{2}}\right)_{\mathrm{T}, \mathrm{P}, \mathrm{x}_{1}}^{\alpha}-\left(\frac{\partial \mathrm{g}^{\mathrm{M}}}{\partial \mathrm{x}_{2}}\right)_{\mathrm{T}, \mathrm{P}, \mathrm{x}_{1}}^{\beta}=0 \\
& \mathrm{~F}_{6} \equiv\left(\frac{\partial \mathrm{g}^{\mathrm{M}}}{\partial \mathrm{x}_{1}}\right)_{\mathrm{T}, \mathrm{P}, \mathrm{x}_{2}}^{\alpha}-\left(\frac{\partial \mathrm{g}^{\mathrm{M}}}{\partial \mathrm{x}_{1}}\right)_{\mathrm{T}, \mathrm{P}, \mathrm{x}_{2}}^{\gamma}=0 \\
& \mathrm{~F}_{7} \equiv\left(\frac{\partial \mathrm{g}^{\mathrm{M}}}{\partial \mathrm{x}_{2}}\right)_{\mathrm{T}, \mathrm{P}, \mathrm{x}_{1}}^{\alpha}-\left(\frac{\partial \mathrm{g}^{\mathrm{M}}}{\partial \mathrm{x}_{2}}\right)_{\mathrm{T}, \mathrm{P}, \mathrm{x}_{1}}^{\gamma}=0 \\
& \mathrm{~F}_{8} \equiv\left(\mathrm{g}^{\mathrm{M}, \beta}-\mathrm{g}^{\mathrm{M}, \alpha}\right)-\left(\mathrm{x}_{1}^{\beta}-\mathrm{x}_{1}^{\alpha}\right)\left(\frac{\partial \mathrm{g}^{\mathrm{M}}}{\partial \mathrm{x}_{1}}\right)_{\mathrm{T}, \mathrm{P}, \mathrm{x}_{2}}^{\alpha}-\left(\mathrm{x}_{2}{ }^{\beta}-\mathrm{x}_{2}{ }^{\alpha}\right)\left(\frac{\partial \mathrm{g}^{\mathrm{M}}}{\partial \mathrm{x}_{2}}\right)_{\mathrm{T}, \mathrm{P}, \mathrm{x}_{1}}^{\alpha}=0 \\
& \mathrm{~F}_{9} \equiv\left(\mathrm{g}^{\mathrm{M}, \gamma}-\mathrm{g}^{\mathrm{M}, \alpha}\right)-\left(\mathrm{x}_{1}^{\gamma}-\mathrm{x}_{1}^{\alpha}\right)\left(\frac{\partial \mathrm{g}^{\mathrm{M}}}{\partial \mathrm{x}_{1}}\right)_{\mathrm{T}, \mathrm{P}, \mathrm{x}_{2}}^{\alpha}-\left(\mathrm{x}_{2}^{\gamma}-\mathrm{x}_{2}{ }^{\alpha}\right)\left(\frac{\partial \mathrm{g}^{\mathrm{M}}}{\partial \mathrm{x}_{2}}\right)_{\mathrm{T}, \mathrm{P}, \mathrm{x}_{1}}^{\alpha}=0
\end{aligned}
$$

where $\alpha, \beta$ and $\gamma$ are the general designations for equilibrium liquid phases.

\subsection{Model parameter estimation}

The optimization of the NRTL parameters has been done by means of the Simplex Flexible method [18], with the objective function defined as:

$$
\text { O.F. }=\min \left[\sum_{\mathrm{k}=1}^{\mathrm{n}} \sum_{\mathrm{i}=1}^{\mathrm{C}} \sum_{\mathrm{l}=1}^{\mathrm{L}}\left[\left(\mathrm{x}_{\mathrm{i}, \mathrm{k}}^{1}\right)_{\exp }-\left(\mathrm{x}_{\mathrm{i}, \mathrm{k}}^{1}\right)_{\text {cal }}\right]^{2}\right]
$$


where $x_{i, k}^{1}$ is the molar fraction of component $i$ on tie-line $k$ and in liquid phase $1(\alpha, \beta, \gamma) ; n$ denotes the total number of tie-lines in the LL and LLL regions; exp and cal stand for experimental and calculated equilibrium data. To correlate the LLL tie-triangle data, it was considered to be divided into three LL pairs of conjugated compositions.

The calculated molar fractions in Eq. (11) have been obtained by solving the set of nonlinear equations (2-10) using the Newton-Raphson method. For the LLLE region (Eq. 510) the algorithm in section 2 is used to define three small and separate composition regions to which each one of the three equilibrium compositions $\mathrm{x}_{\mathrm{i}}^{\alpha}, \mathrm{x}_{\mathrm{i}}{ }^{\beta}$ and $\mathrm{x}_{\mathrm{i}}^{\gamma}$ are restricted.

A constant value was used for the NRTL non-randomness parameter alpha $\left(\alpha_{\mathrm{ij}}\right)$ during the initial stage of the correlation process. It was set to 0.2 , a value frequently used in the literature [17]. After that, the correlations were carried out again, but now considering $\alpha_{\mathrm{ij}}$ as an optimization parameter to check if any improvement in the results could be achieved.

\section{Data correlation results and discussion}

Tie-lines (LLE) and the tie-triangle (LLLE) experimental data of the following systems have been correlated using the suggested procedure:

- System A: 1-Hexanol(1)-Nitromethane(2)-Water(3), 21 ${ }^{\circ} \mathrm{C}$ [13].

- System B: 1-Nonanol(1)-Nitromethane(2)-Water(3), 23º C [13].

- System C: Lauryl Alcohol(1)-Nitromethane(2)- Glycol(3), $22^{\circ} \mathrm{C}$ [19].

Tables 1, 2 and 3 show the NRTL parameters obtained for the systems A, B and C, respectively, the accuracy of the data fit provided by the objective function (O.F.) Eq. (11), and the standard deviation, obtained by means of the following equation:

$\sigma=100 \times \sqrt{\frac{\sum_{\mathrm{k}=1}^{\mathrm{n}} \sum_{\mathrm{i}=1}^{\mathrm{C}} \sum_{\mathrm{l}=1}^{\mathrm{L}}\left(\left(\mathrm{x}_{\mathrm{i}, \mathrm{k}}^{1}\right)_{\exp }-\left(\mathrm{x}_{\mathrm{i}, \mathrm{k}}^{1}\right)_{\mathrm{cal}}\right)^{2}}{2 \cdot \mathrm{C} \cdot \mathrm{n}}}$ 
Initially, only the LLE binary data were correlated with the NRTL model, and the ternary equilibrium data were predicted from the binary parameters obtained as a result (Table 1). The high values for the mean deviation between experimental and calculated equilibrium data $\left(\sigma_{\mathrm{A}}=3.61, \sigma_{\mathrm{B}}=11.79, \sigma_{\mathrm{C}}=6.64\right)$ for the three systems illustrate the lack in ability of the NRTL model to accurately represent the experimental ternary data using exclusively binary equilibrium data.

After that, ternary tie-lines (LLE) and the tie-triangle (LLLE) experimental data were simultaneously correlated for each one of the three ternary systems. At first, correlations were carried out with a nonrandomness factor $\alpha_{\mathrm{ij}}$ (NRTL) of 0.2. However, high values still resulted for the deviations of the three systems $\left(\sigma_{A}=3.06, \sigma_{B}=5.93, \sigma_{C}=5.14\right)$. Table 2 shows the $\mathrm{A}_{\mathrm{ij}}$ parameters together with the accuracy of the data fit given by the objective function and the standard deviation.

Next, $\alpha_{\mathrm{ij}}$ was taken as an additional optimization parameter, in order to check if an improvement in the results could be achieved [20]. The accuracy of the fittings improved markedly for systems A and C, although the deviations were still considerably high $\left(\sigma_{\mathrm{A}}=2.04\right.$, $\sigma_{C}=4.60$ ). For system $B$, the optimization of $\alpha_{\mathrm{ij}}$ did not improve the quality of the fitting. Table 3 shows the $\mathrm{A}_{\mathrm{ij}}$ parameters and the nonrandomness factors $\alpha_{\mathrm{ij}}$, as well as the accuracy of the data fit given by the objective function and the standard deviation.

Experimental and calculated results for systems A, B and C are shown in Figures 9, 10 and 11, respectively. The prediction (from binary LLE data) of, and best correlation results for the ternary equilibrium data have been included for comparison. There it can be observed that it is qualitatively possible to fit all the regions with the NRTL equation using the same set of $\mathrm{A}_{\mathrm{ij}}$ parameters, though a large deviation is obtained in some cases. In system $\mathrm{A}$, the LLLE (tie-triangle) fitting leads to a small deviation in the calculated equilibrium data for the 1-3 binary subsystem. The same occurs with system $C$, where additionally, the 1-2 binary 
subsystem also displays substantial deviations. In system $\mathrm{B}$, for the calculated tie-triangle to approach the experimental one, it is required that the LLE calculated compositions for the 1-2 binary subsystem be much closer to one another and, therefore, very far from the experimental one. In this case, the NRTL model seems not to be flexible enough to simultaneously reproduce the very narrow LLLE tie-triangle and the LLE data for the 1-2 binary subsystem. The NRTL lines predicted for system B (Fig.10) demonstrate that compatibility with LLE data for the 1-2 binary subsystem is only possible for a much larger tie-triangle than the experimental one.

The above results illustrate the necessity of developing new more capable models able to reproduce the equilibrium behaviour of these complex systems accurately $[21,22]$, as in the case of type 3 ternary systems including a LLLE region.

For all the parameter sets presented in this paper, it has been verified that the calculated tie-lines and tie-triangles were contained in planes tangent to the $\mathrm{g}^{\mathrm{M}}$ surface that did not intersect with the Gibbs energy surface at any other point. This guaranteed that they were all stable equilibrium solutions.

\section{Conclusions}

A procedure to carry out simultaneous correlation of the LLE and LLLE regions in type 3 systems has been presented. This procedure is based on the common tangent plane criterion as equilibrium condition and looks for the three very small areas of the composition space where the LLL equilibrium solution must be found by means of a process of sequential confinement. This method allows for fast convergence because it introduces a guided search and avoids false and trivial equilibrium solutions as well as the need to define a global mixture inside the tie-triangle. 
It has been ascertained by examining the results obtained, that through the NRTL model it is qualitatively possible to find binary parameters that simultaneously generate all the equilibrium regions for this type of ternary systems. Nevertheless, deviations between experimental and calculated equilibrium data for some of these systems are too high, so the lack in ability of the NRTL equation to model this type of system has thus been demonstrated. In these systems, many topological conditions must be fulfilled by the Gibbs energy surface in order to simultaneously reproduce the system behaviour in all the equilibrium regions, as is

required by the tangent plane criterion. Therefore, models for the liquid $\mathrm{g}^{\mathrm{M}}$ function need to be more flexible in order to simultaneously represent the phase equilibria of complex systems having different equilibrium regions.

\section{Nomenclature}

$\begin{array}{ll}A_{i j} & \text { Binary interaction parameters }(\mathrm{K}) \text { for components } \mathrm{i}, \mathrm{j} . \\ \alpha_{i j} & \text { Non-randomness NRTL factor. } \\ G^{E} & \text { Excess Gibbs energy }\left(\mathrm{J} \cdot \mathrm{mol}^{-1}\right) \\ G^{i d} & \text { Ideal Gibbs energy of mixing }\left(\mathrm{J} \cdot \mathrm{mol}^{-1}\right) \\ G^{M}, g^{M} & \text { Gibbs energy of mixing }(\mathrm{J} / \mathrm{mol} \text { and dimensionless, respectively) } \\ g^{M}{ }_{\text {Min }} & \text { global minimum Gibbs energy of mixing (dimensionless) } \\ T & \text { Temperature (K) } \\ N & \text { Tie-line number } \\ C & \text { Number of components } \\ L & \text { Number of Liquid Phases } \\ L L E & \text { Liquid-liquid equilibrium } \\ L L L E & \text { Liquid-liquid-liquid equilibrium }\end{array}$

Superscripts

$1 \quad$ Liquid Phase

$\alpha, \beta, \gamma \quad$ Equilibrium liquid phases 


\section{Subscripts}
$i, j \quad$ Components $\mathrm{i}, \mathrm{j}$
exp Experimental value
cal Calculated value

\section{Acknowledgements}

The authors gratefully acknowledge financial support from the Vicepresidency of Research (University of Alicante) and Generalitat Valenciana (GV/2007/125).

\section{References}

[1] R.E. Treybal, Extracción en fase líquida, first ed., UTEHA, 1968

[2] R. Stateva, P. Cholakov, S. Georgi, A.A. Galushko, W.A. Wakeham, Chem. Eng. Sci. 55 (2000) 2121-2129.

[3] M. Kahlweit, R. Strey, G. Busse, J. Phys Chem. 94 (1990) 3881-3894.

[4] J.G. Andersen, N. Koak, T.W. de Loos, Fluid Phase Equilib. 163 (1999) 259-273.

[5] Z. Huan, G. H. Van Bochove, T.W. de Loos, Thermodynamics. 49 (2003) 745.

[6] F. García-Sanchez, J. Schwartzentruber, M.N. Ammar, H. Renon, Fluid Phase Equilib. 121 (1996) 207-225.

[7] B.M. Knickerbocker, C.V. Pesheck, L.E. Scriven, H.T. David, J. Phys Chem. 83 (1979) 1984-1990.

[8] B.M.; Knickerbocker, C.V. Pesheck, H.T. Davis, L.E.; Scriven, J. Phys Chem. 86 (1982) 393-400.

[9] C.M. McDonald, C.A. Floudas, AIChE J. 41 (1995) 1798-1814.

[10] C.M. McDonald, C.A. Floudas, Comput. Chem. Eng. 21 (1997) 1-23.

[11] R.A. Heidemann, R.M. Abdel-Ghani, Chem. Eng. Sci. 56 (2001) 6873- 6881.

[12] H. Renon, J. M. Prausnitz, AIChE J. 14 (1968) 135-142. 
[13] J.M. Sørensen, W. Artl, Liquid-Liquid Equilibrium Data Collection. Chemistry Data Series, Vol. V, Part 2, DECHEMA, 1980

[14] D.S. Abrams, J.M. Prausnitz, AIChE J. 21 (1975) 116-128.

[15] S.K. Wasylkiewicz, L.N. Sridhar, M.F. Doherty, M.F Malone, Ind. Eng. Chem. Res. 35 (1996) 1395-1408.

[16] G.A. Iglesias-Silva, A. Bonilla-Petriciolet, P.T. Eubank, J.C. Holste, Hall, K.R., Fluid Phase Equilib. 210 (2003), 229-245.

[17] J.M. Prausnitz, R.N. Lichtenthaler, E. Gomes de Acevedo, Molecular Thermodynamics of Fluid-Phase Equilibria, third ed, Prentice Hall PTR: Upper Saddle River, 1999

[18] D.M. Himmelblau, Process Analysis Statistical Methods. John Willey \& Sons, 1968

[19] A.W. Francis, J. Phys. Chem. 60 (1956) 20-27.

[20] J.A. Reyes-Labarta, M.M. Olaya, R. Velasco, M.D. Serrano, A. Marcilla, Fluid Phase Equilib. 278 (2009) 9-14.

[21] M.M. Olaya, J.A. Reyes-Labarta, R. Velasco, I. Ibarra, A. Marcilla, Fluid Phase Equilib. 265 (2008) 184-191.

[22] A. Marcilla, J.A. Reyes-Labarta, M.M. del Mar Olaya, M.D. Serrano, Ind. Eng. Chem. Res. 47 (2008) 2100-2108. 


\section{List of tables}

Table 1. Binary parameters $A_{i j}(K)$ used for the ternary LLE and LLLE prediction with NRTL $(\alpha=0.2)$ for systems A, B and C; objective function (O.F) and standard deviation $(\sigma)$.

Table 2. Correlation results (NRTL) for systems A, B and C; Binary parameters $A_{i j}(K)$, objective function (O.F) and the standard deviation $(\sigma)$.

Table 3. Correlation results (NRTL) for systems $A$ and $C$; Binary parameters $A_{i j}(K)$, nonrandomness factor $\alpha_{\mathrm{ij}}$, objective function (O.F) and the standard deviation $(\sigma)$.

\section{List of captions}

Fig. 1. Liquid phase equilibrium diagrams for type 3 ternary systems (Treybal, 1980): a) three LL regions, b) two LL regions, and c) three LL regions and one LLL region (tie-triangle).

Fig. 2. Representation of the $\mathrm{g}^{\mathrm{M}}$ surface (NRTL) for a type 3 ternary system including a LLLE region $\left(\mathrm{A}_{12}=550 \mathrm{~K} ; \mathrm{A}_{21}=400 \mathrm{~K} ; \mathrm{A}_{13}=600 \mathrm{~K} ; \mathrm{A}_{31}=500 \mathrm{~K} ; \mathrm{A}_{23}=600 \mathrm{~K} ; \mathrm{A}_{32}=500 \mathrm{~K} ;\right.$ $\left.\alpha=0.2, \mathrm{~T}=25^{\circ} \mathrm{C}\right)$.

Fig. 3. Representation of the $\mathrm{g}^{\mathrm{M}}$ curve (NRTL) for a partially miscible binary system $\left(\mathrm{A}_{12}=600 \mathrm{~K} ; \mathrm{A}_{21}=500 \mathrm{~K} ; \alpha=0.2, \mathrm{~T}=25^{\circ} \mathrm{C}\right)$.

Fig. 4. Representation of the $\mathrm{g}^{\mathrm{M}}$ surface (NRTL) for a type 3 ternary system including a LLLE region (parameters in Fig.1). Selection of the binary subsystem to form a plane with the $\mathrm{g}^{\mathrm{M}}$ global minimum.

Fig. 5. Representation of the $\mathrm{g}^{\mathrm{M}}$ surface (NRTL) for a type 3 ternary system including a LLLE region (parameters in Fig. 2). First step towards confinement of the LLLE solution (intersection between $\mathrm{g}^{\mathrm{M}}$ and the plane $\mathrm{P} 1$ ); gives rise to three separate confinement regions.

Fig. 6. Representation of the $\mathrm{g}^{\mathrm{M}}$ surface (NRTL) for a type 3 ternary system including a LLLE region $\left(\mathrm{A}_{12}=550 \mathrm{~K} ; \mathrm{A}_{21}=300 \mathrm{~K} ; \mathrm{A}_{13}=600 \mathrm{~K} ; \mathrm{A}_{31}=500 \mathrm{~K} ; \mathrm{A}_{23}=800 \mathrm{~K} ; \mathrm{A}_{32}=500 \mathrm{~K} ;\right.$ 
$\alpha=0.2, T=25^{\circ} \mathrm{C}$ ). First step towards confinement of the LLLE solution (intersection between $\mathrm{g}^{\mathrm{M}}$ and the plane $\left.\mathrm{P} 1\right)$; gives rise to two separate confinement regions.

Fig. 7. a) Projection of the $\mathrm{g}^{\mathrm{M}}$ surface (parameters in Fig. 6) and plane P1. b) Evaluation of the $\mathrm{g}^{\mathrm{M}}$ surface intersections between $\mathrm{P} 1$ and $\mathrm{g}^{\mathrm{M}}$ within the cross sections: $\mathrm{S} 1, \mathrm{~S} 2$ and $\mathrm{S} 3$. Definition of a new plane P2 using points $i, j$ and $h$.

Fig. 8. Representation of the $\mathrm{g}^{\mathrm{M}}$ surface (parameters in Fig. 6) for a type 3 ternary system with a LLLE region: a) Intersection of the plane $\mathrm{P} 2$ with the $\mathrm{g}^{\mathrm{M}}$ surface, and b) projection to show the three small regions that contain the LLLE solution.

Fig. 9. Experimental and calculated data; prediction (Table 1) and correlation (Table 3); for the system 1-Hexanol(1) + Nitromethane(2) + Water(3) at T=294 K.

Fig. 10. Experimental and calculated data; prediction (Table 1) and correlation (Table 2); for the system 1-Nonanol(1) + Nitromethane(2) + Water(3), at T=296 K.

Fig. 11. Experimental and calculated data; prediction (Table 1) and correlation (Table 3); for the system Lauryl Alcohol(1) + Nitromethane(2) + Glycol(3) at T=295 K. 
Table 1. NRTL Binary parameters $A_{i j}(K)$ used for the ternary LLE and LLLE prediction $(\alpha=0.2)$ for systems A, B and C; objective function (O.F) and standard deviation $(\sigma)$.

\begin{tabular}{ccccccccc}
\hline System & $\mathbf{A}_{\mathbf{1 2}}$ & $\mathbf{A}_{\mathbf{2 1}}$ & $\mathbf{A}_{\mathbf{1 3}}$ & $\mathbf{A}_{\mathbf{3 1}}$ & $\mathbf{A}_{\mathbf{2 3}}$ & $\mathbf{A}_{\mathbf{3 2}}$ & $\mathbf{F . O .}$ & $\boldsymbol{\sigma}$ \\
\hline $\mathrm{A}$ & 114.27 & 1069.6 & 131.04 & 3217.8 & 455.24 & 738.24 & $4.68 \cdot 10^{-2}$ & 3.61 \\
\hline $\mathrm{B}$ & 160.24 & 755.94 & -86.336 & 2032.1 & 447.51 & 744.12 & 0.501 & 11.8 \\
\hline $\mathrm{C}$ & 293.49 & 1148.7 & -254.69 & 1700.9 & 894.68 & 58.604 & 0.160 & 6.68 \\
\hline
\end{tabular}

Table 2. Correlation results (NRTL) for systems A, B and C, $\alpha=0.2$; Binary parameters $A_{i j}$ $(\mathrm{K})$, objective function (O.F) and the standard deviation $(\sigma)$.

\begin{tabular}{ccccccccc}
\hline System & $\mathbf{A}_{\mathbf{1 2}}$ & $\mathbf{A}_{\mathbf{2 1}}$ & $\mathbf{A}_{\mathbf{1 3}}$ & $\mathbf{A}_{\mathbf{3 1}}$ & $\mathbf{A}_{\mathbf{2 3}}$ & $\mathbf{A}_{\mathbf{3 2}}$ & $\mathbf{F . O .}$ & $\boldsymbol{\sigma}$ \\
\hline $\mathrm{A}$ & 114.46 & 1064.1 & 74.871 & 3332.4 & 460.25 & 725.16 & $3.3 \cdot 10^{-2}$ & 3.06 \\
\hline $\mathrm{B}$ & 163.46 & 577.60 & -2.3341 & 1060.9 & 492.78 & 564.33 & 0.126 & 5.93 \\
\hline $\mathrm{C}$ & 255.90 & 1213.3 & -319.02 & 1696.6 & 864.89 & 62.801 & $9.5 \cdot 10^{-2}$ & 5.14 \\
\hline
\end{tabular}

Table 3. Correlation results (NRTL) for systems A and C; Binary parameters $A_{i j}(K)$, nonrandomness factor $\alpha_{\mathrm{ij}}$, objective function (O.F) and the standard deviation $(\sigma)$.

\begin{tabular}{cccccccccccc}
\hline System & $\mathbf{A}_{12}$ & $\mathbf{A}_{21}$ & $\mathbf{A}_{13}$ & $\mathbf{A}_{31}$ & $\mathbf{A}_{23}$ & $\mathbf{A}_{32}$ & $\alpha_{12}$ & $\alpha_{13}$ & $\alpha_{23}$ & F.O. & $\sigma$ \\
\hline $\mathrm{A}$ & 164.79 & 985.64 & -512.72 & 2827.5 & 449.19 & 700.40 & 0.21 & 0.13 & 0.23 & $1.5 \cdot 10^{-2}$ & 2.04 \\
\hline $\mathrm{C}$ & 258.44 & 1208.6 & -308.81 & 1686.5 & 864.36 & 63.338 & 0.23 & 0.22 & 0.19 & $7.6 \cdot 10^{-2}$ & 4.60 \\
\hline
\end{tabular}


Click here to download high resolution image

a)

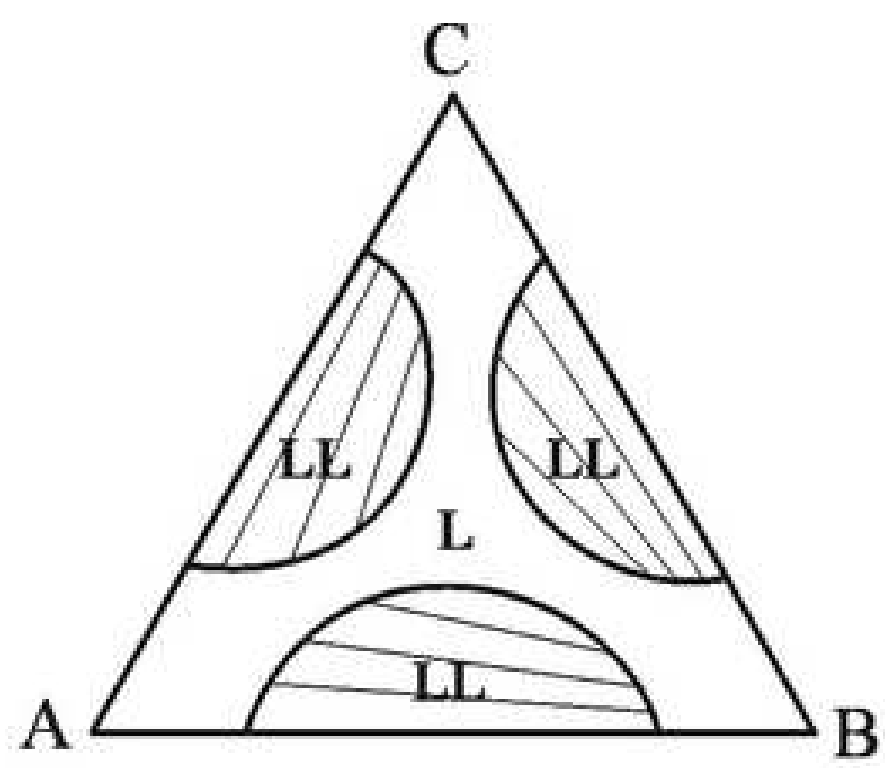

b)

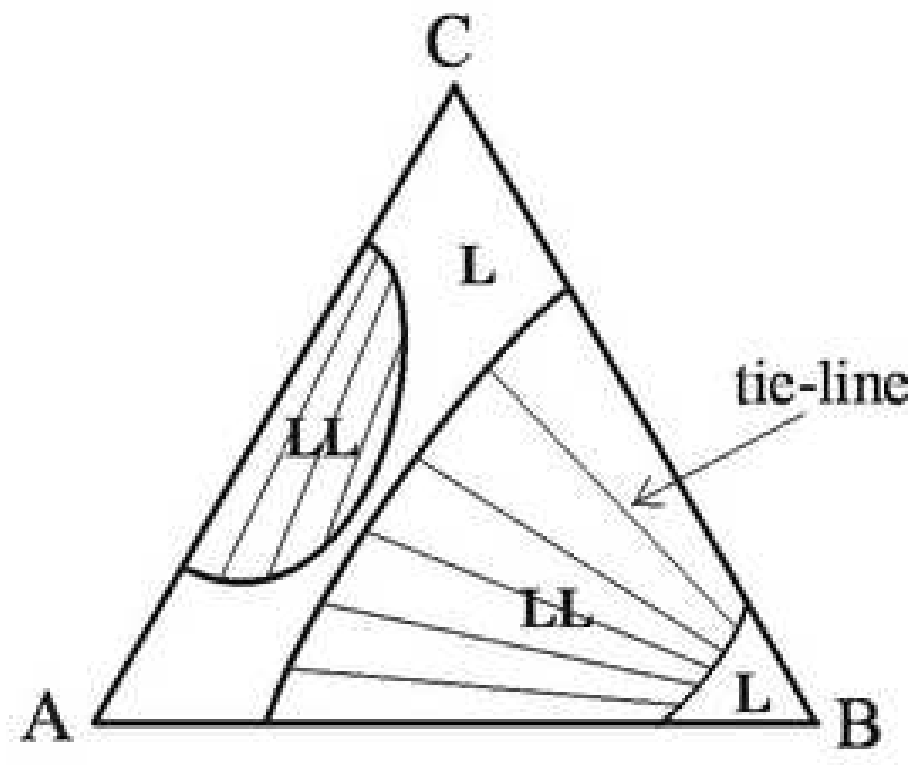

c)

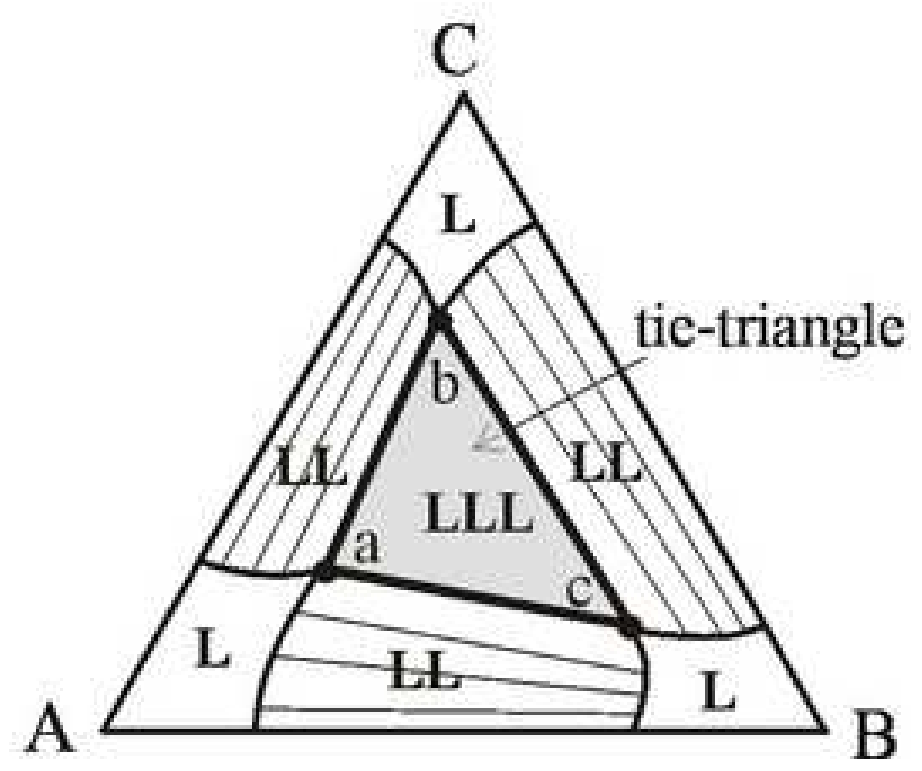




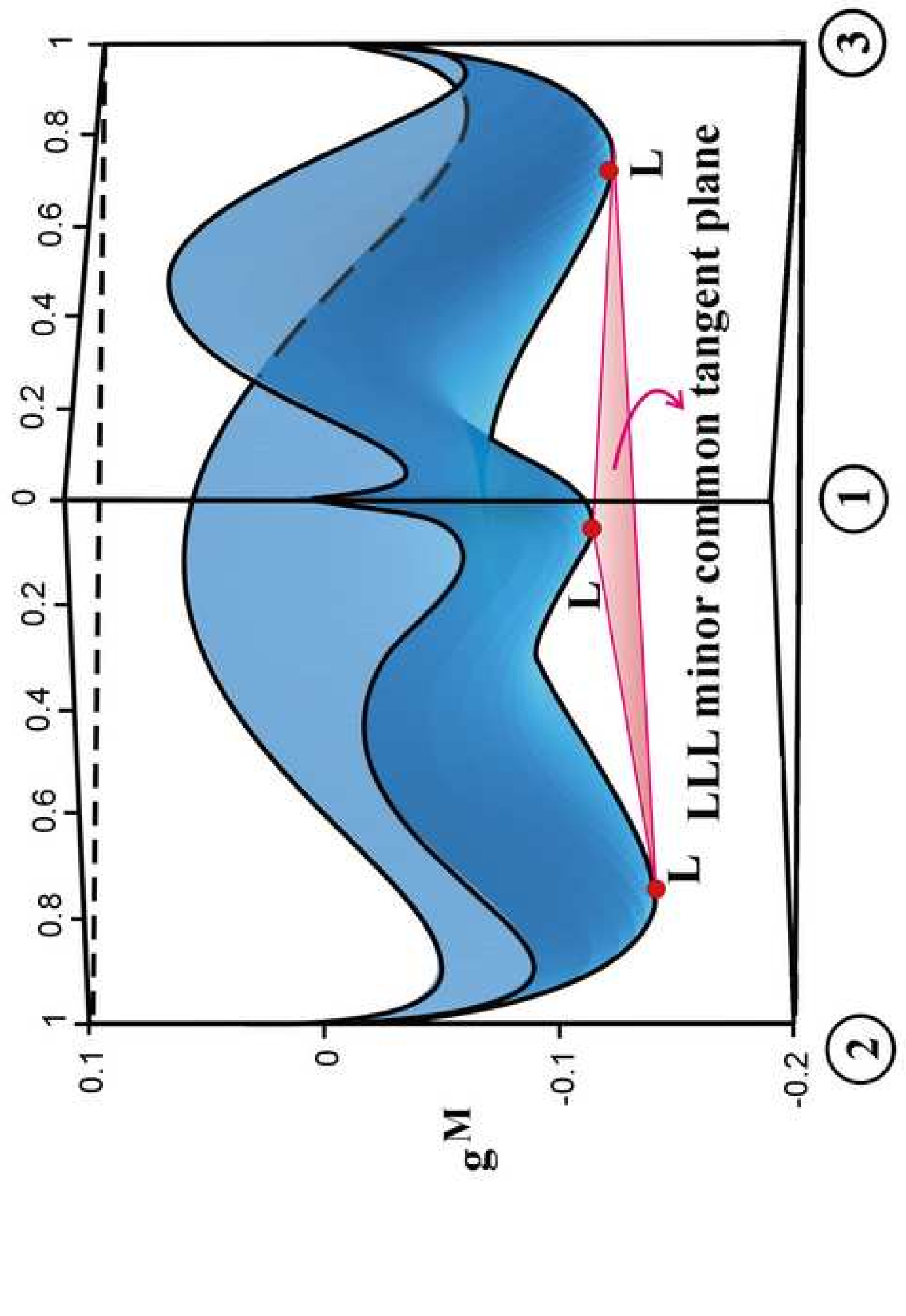



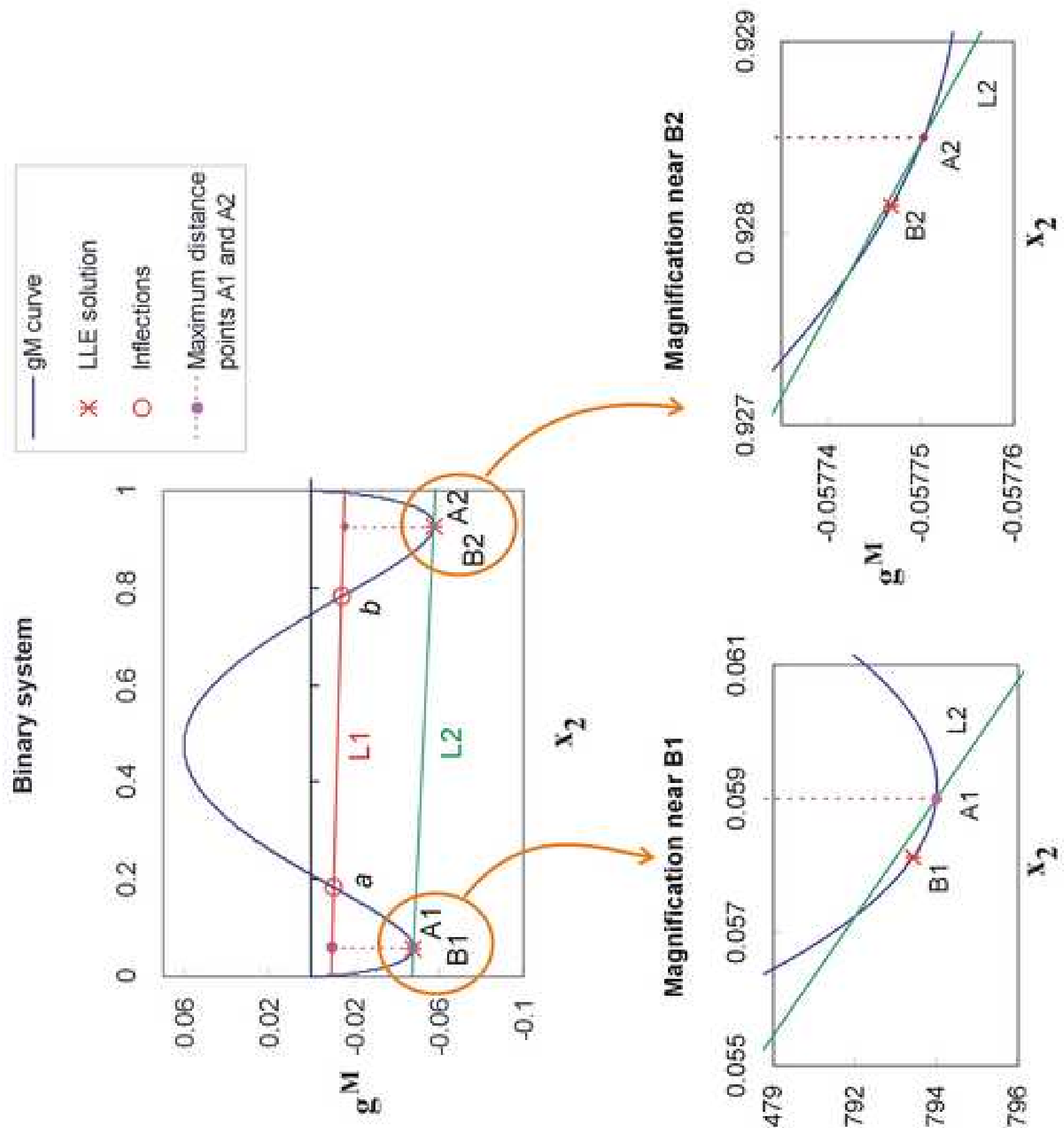

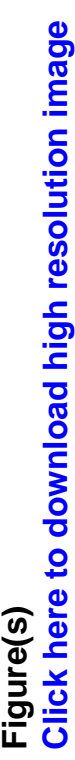

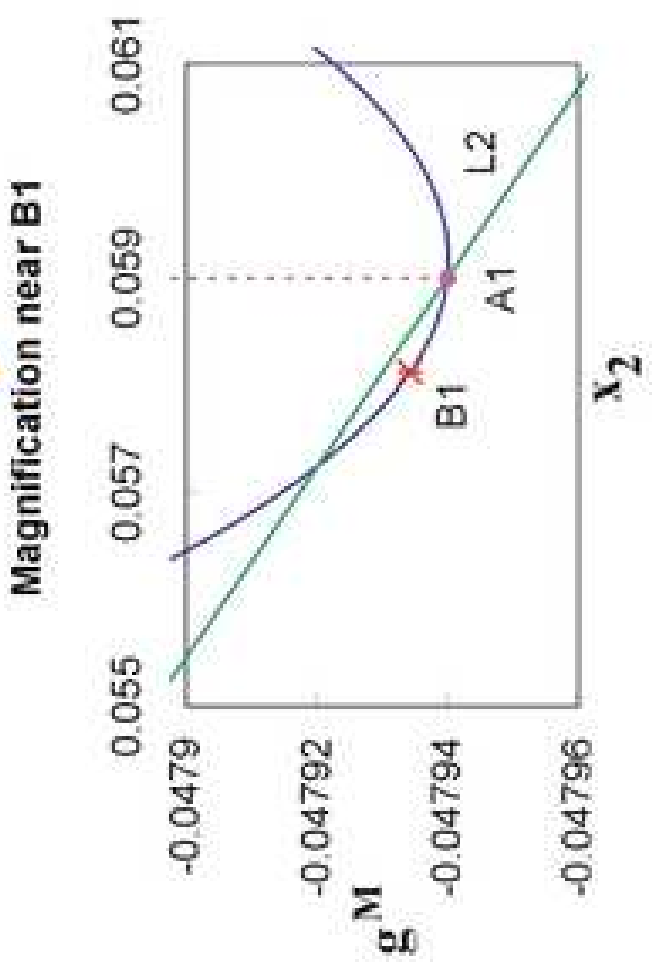




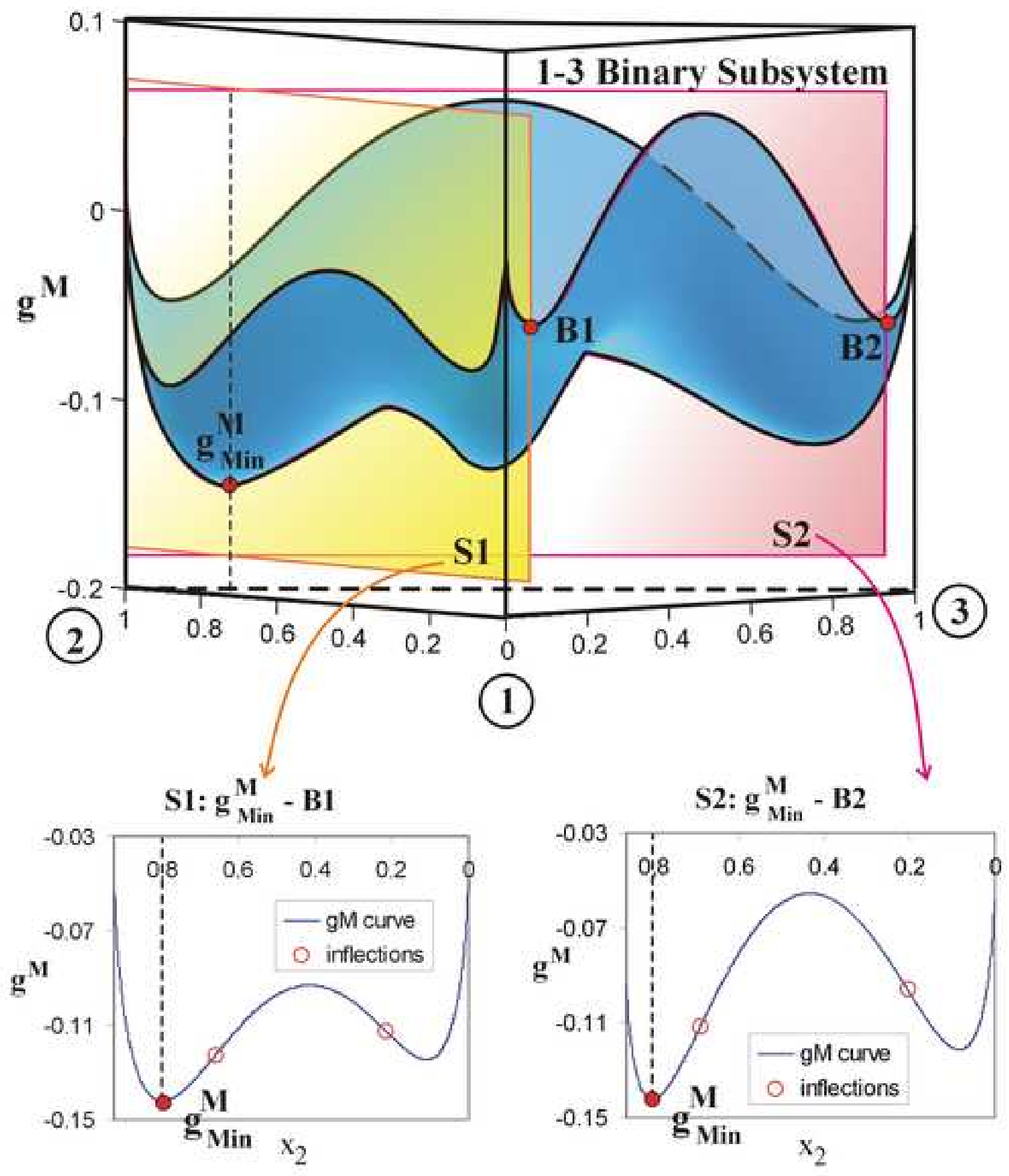


(2)

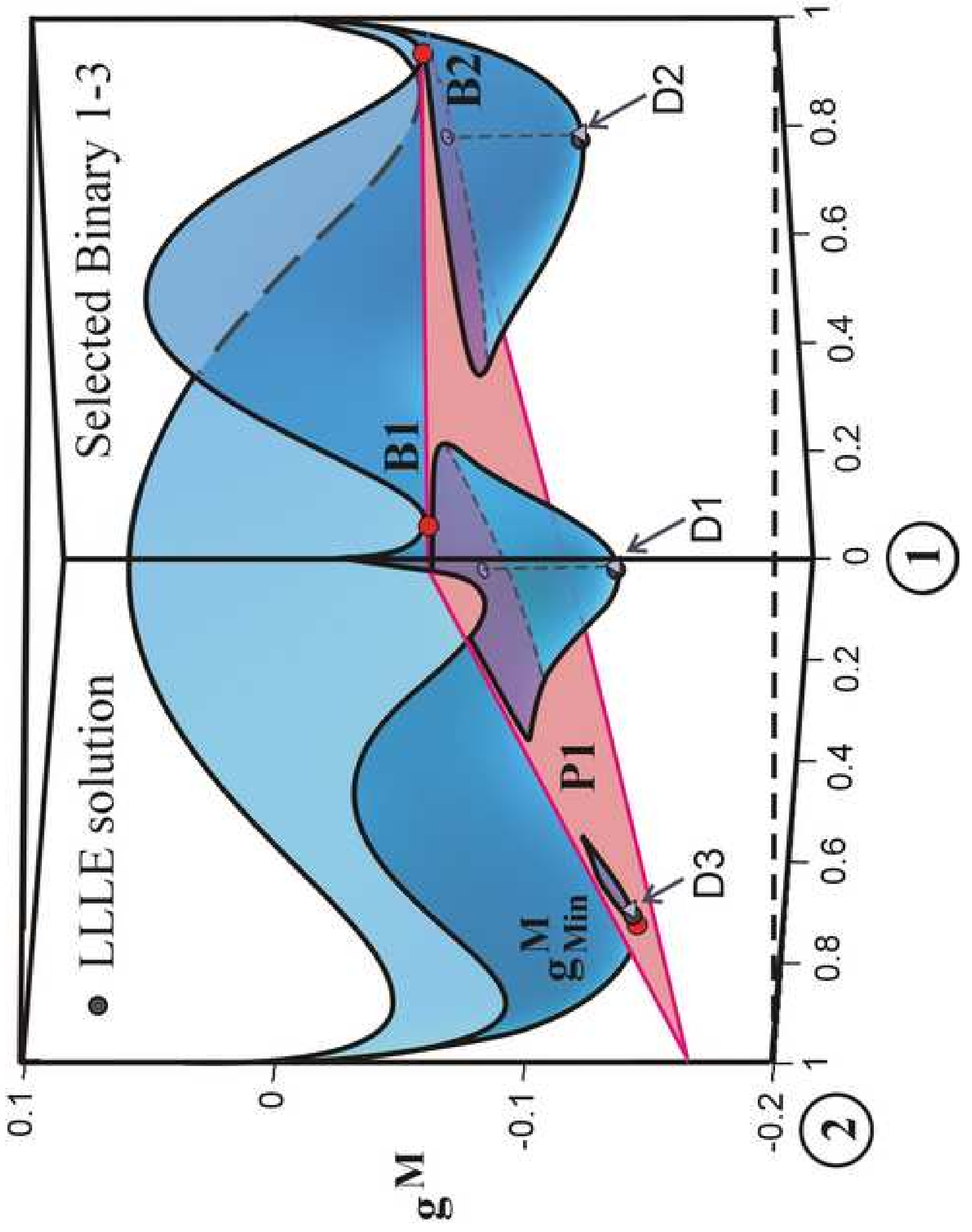


(2)

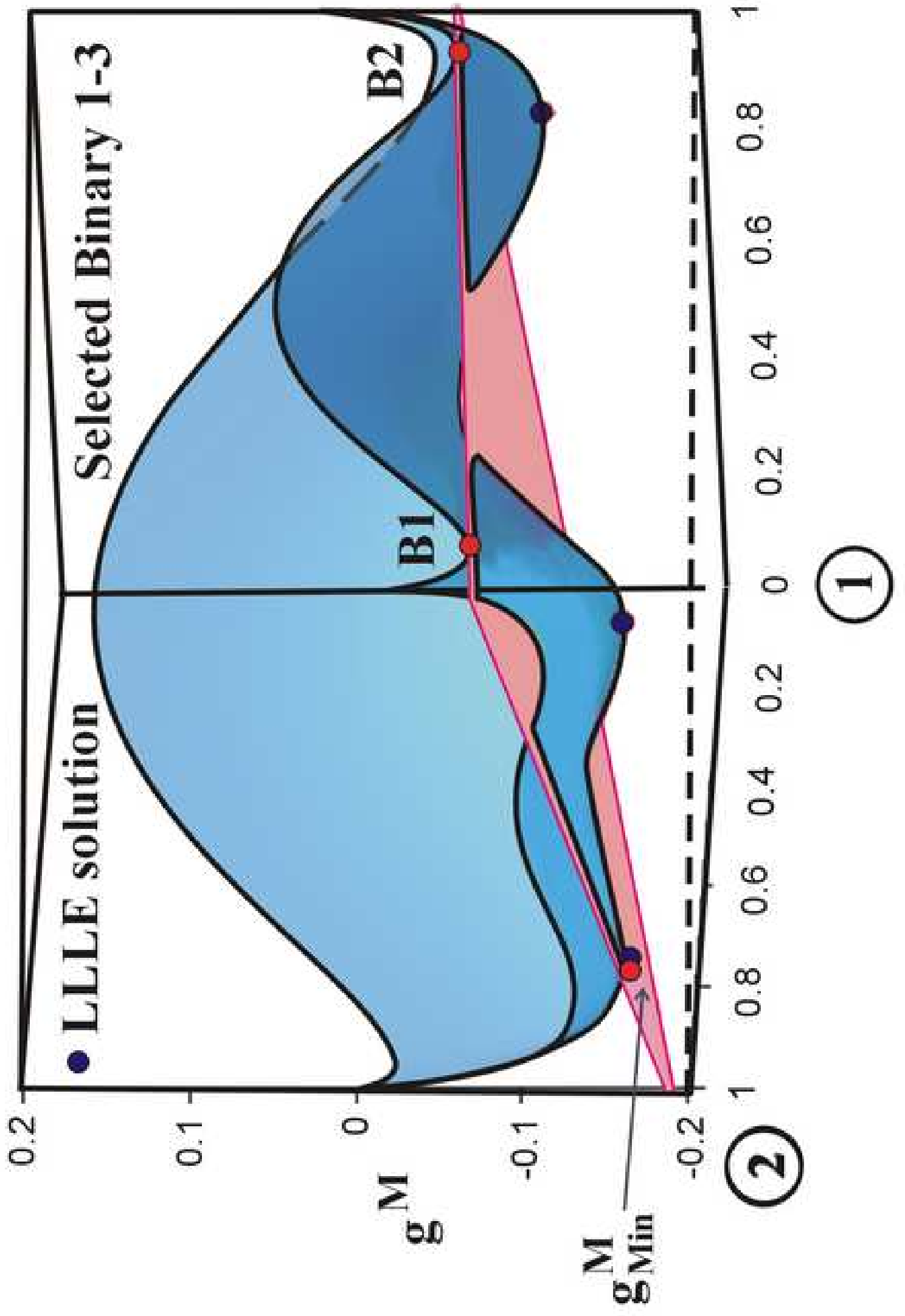

क

列

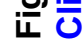




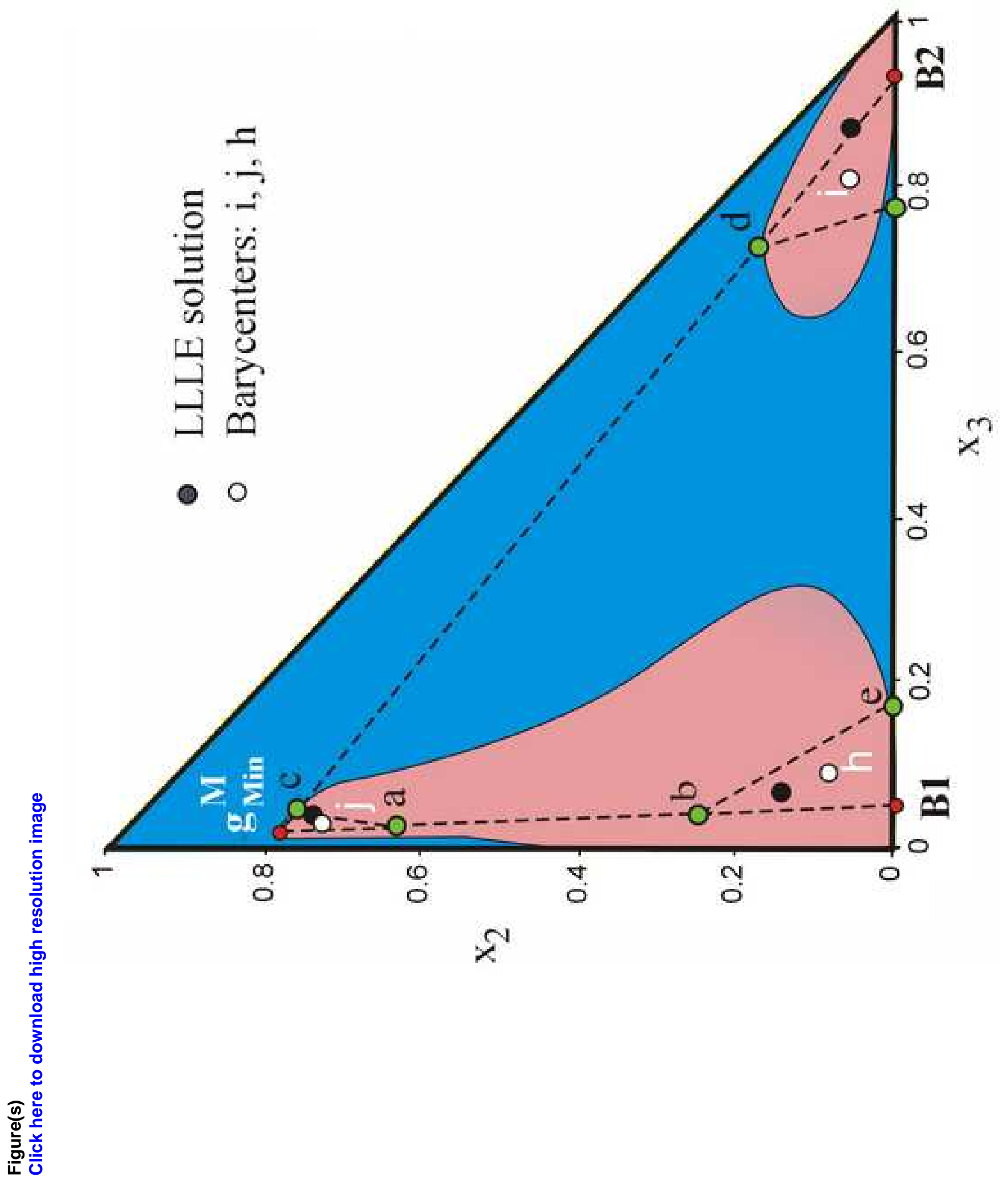



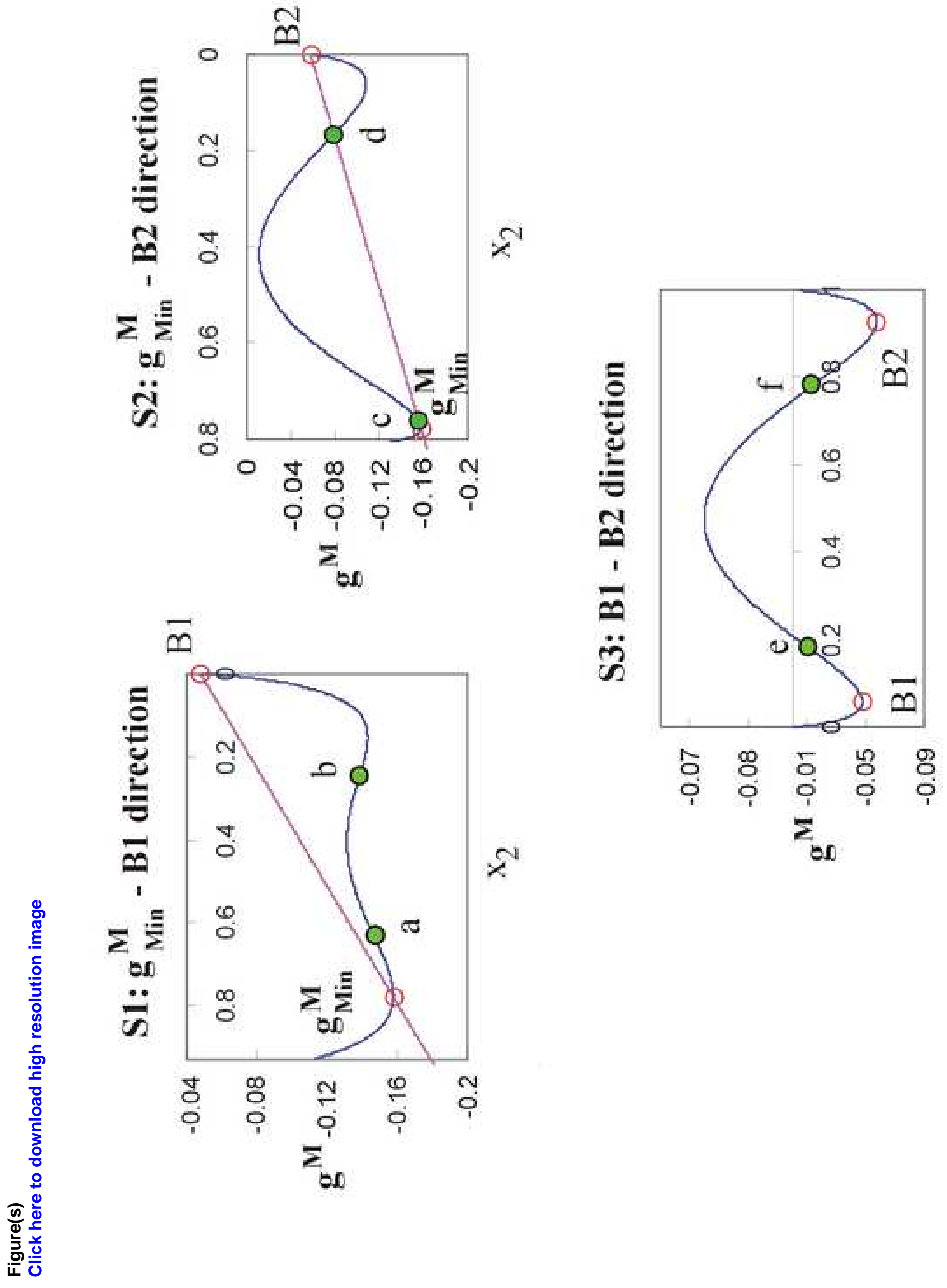

$x$ 


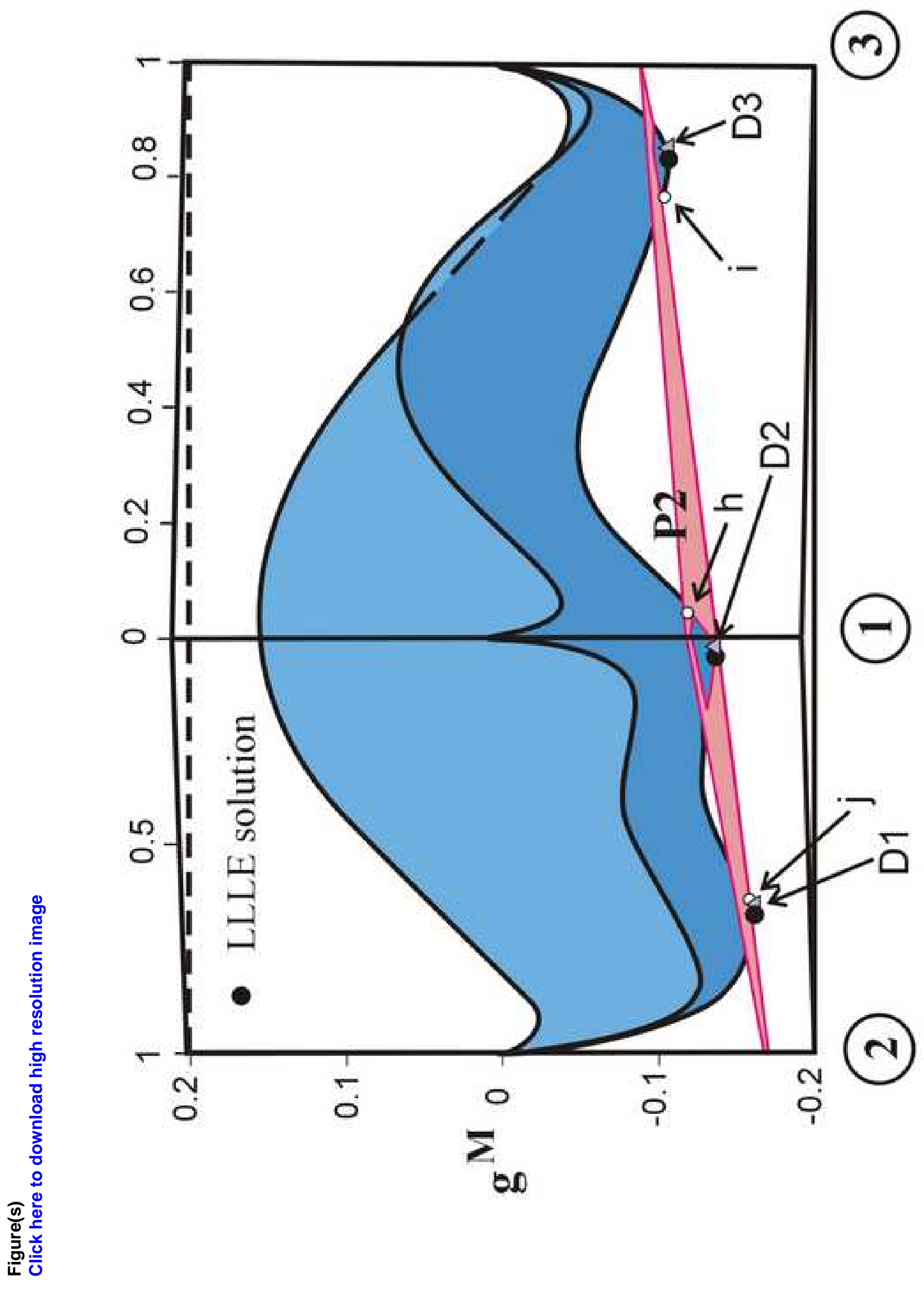




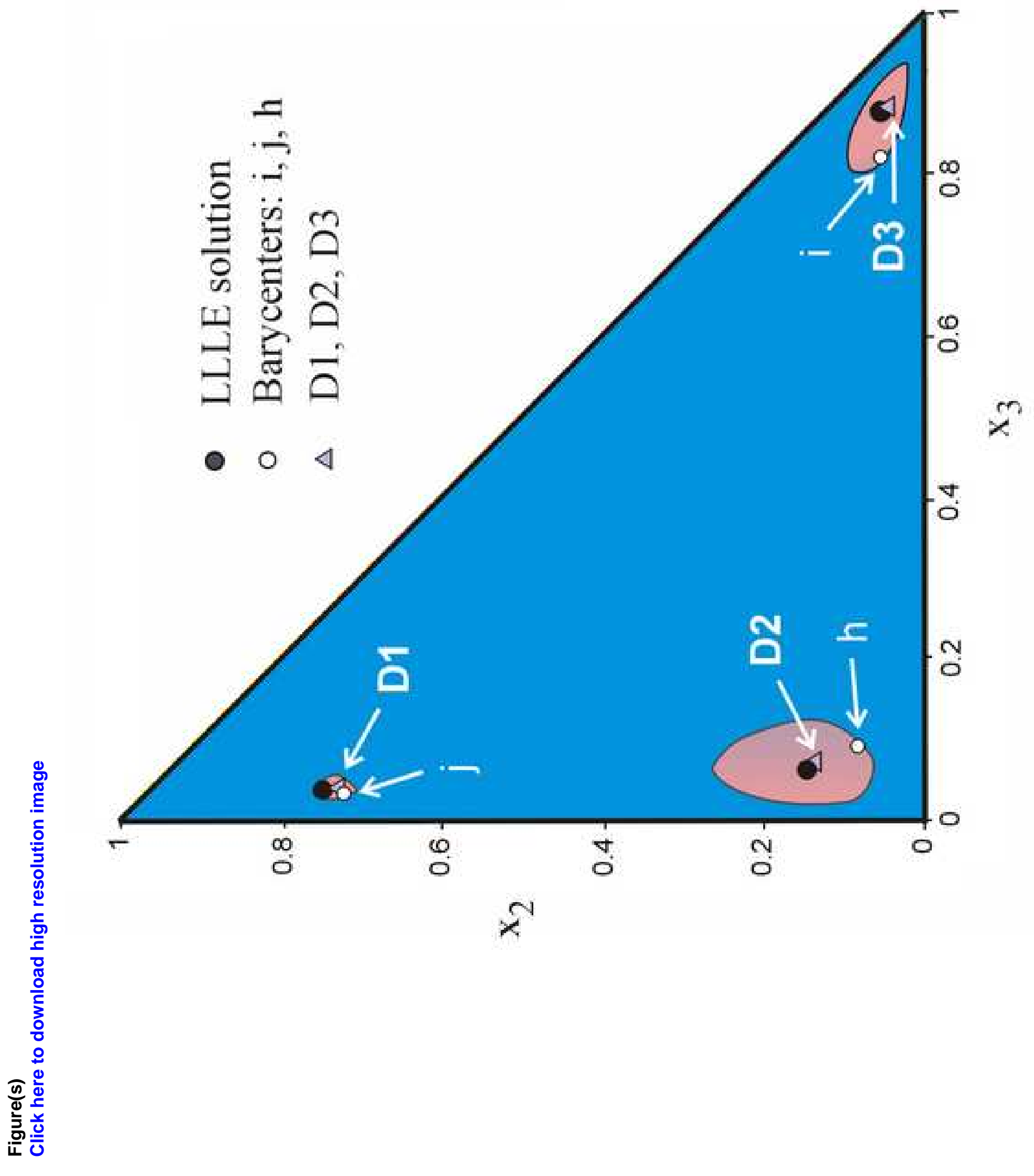




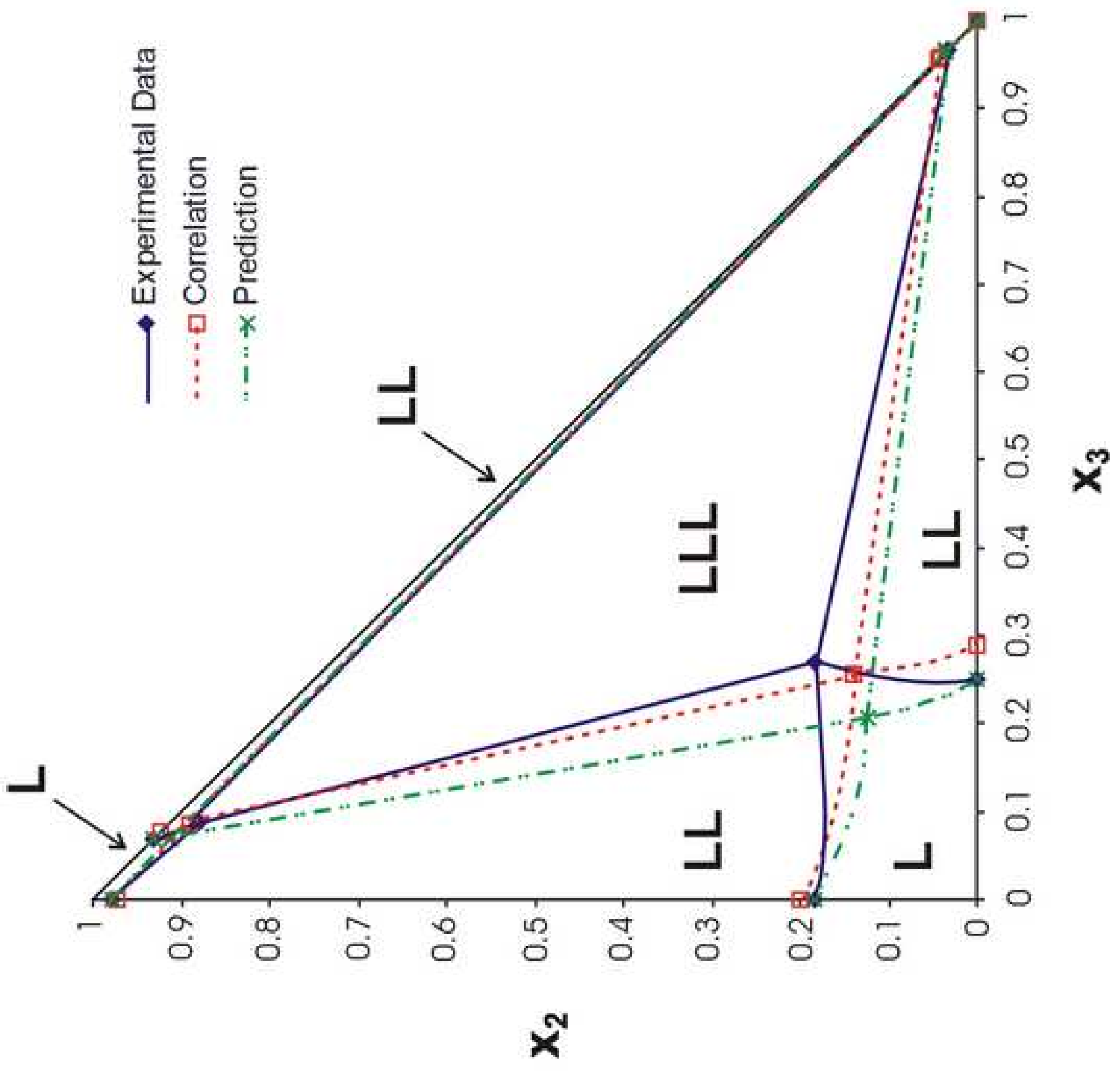




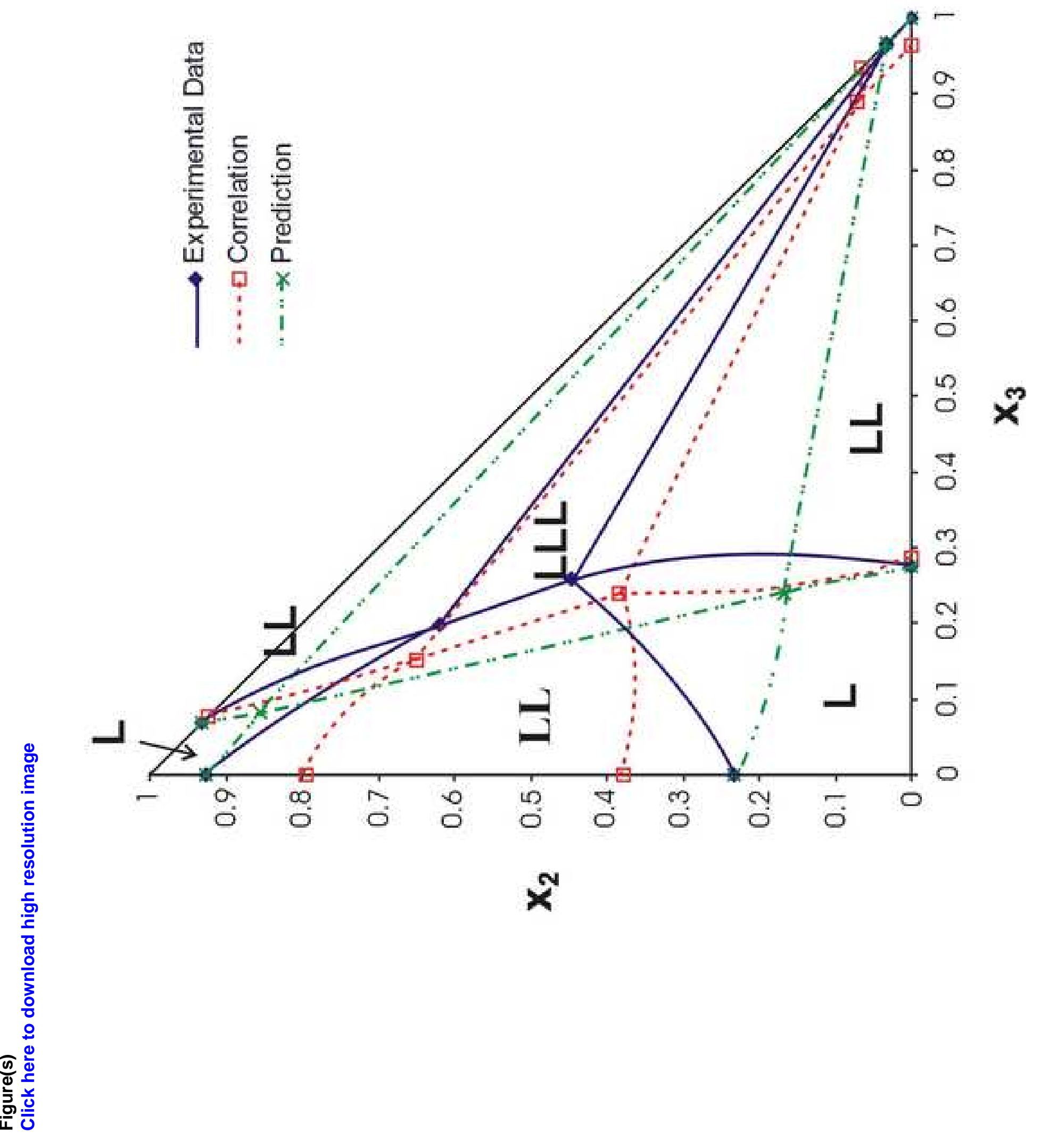




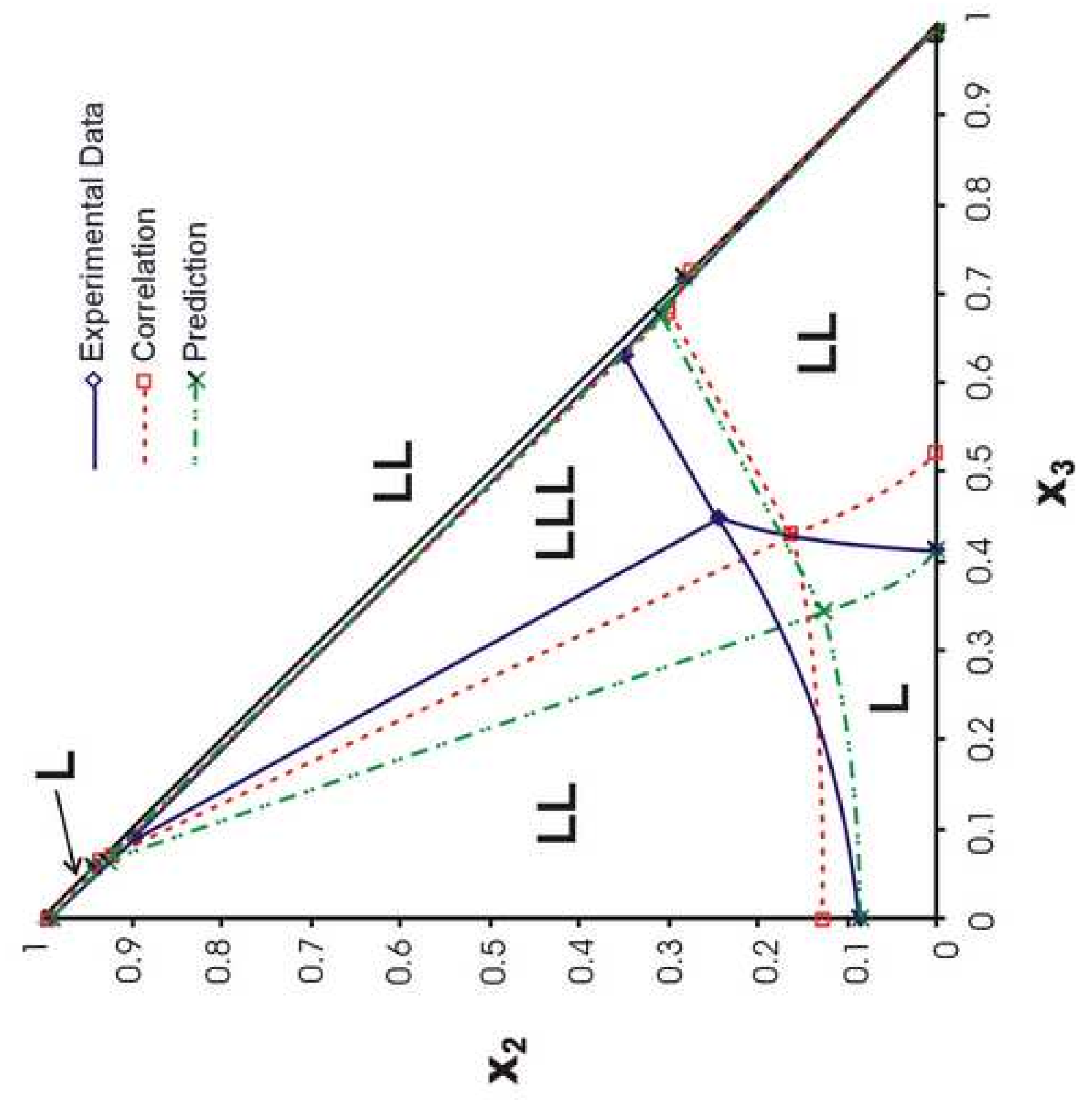


Click here to download Supplementary Material: FiguresjpgBW_Correlation_LLLE_Type3_JAReyesLabarta.rar 